\title{
Black flies
}

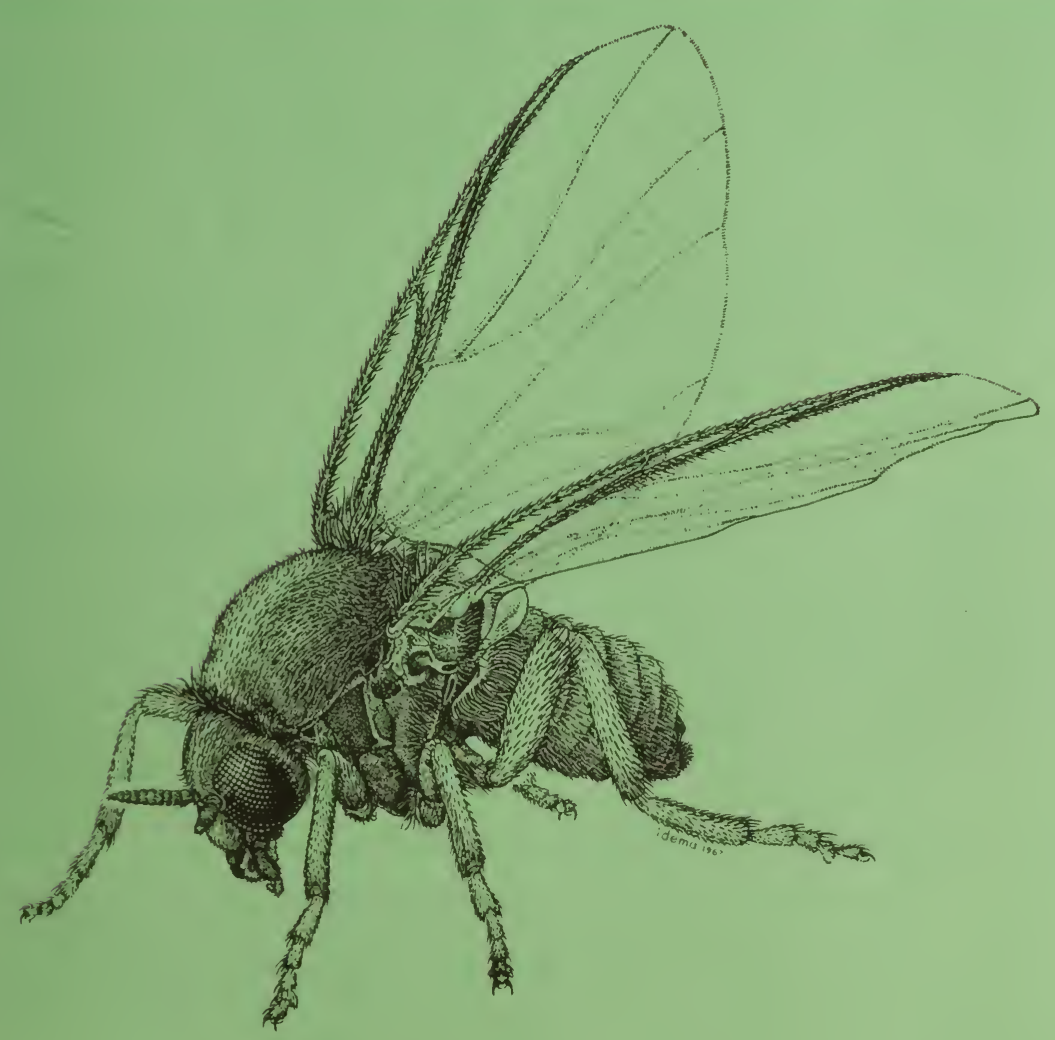





\section{Black flies}

P.G. Mason

Research Station

Saskatoon, Sask.

J.A. Shemanchuk

Research Station

Lethbridge, Alta.

Recommendations for pesticide use in this publication are intended as guidelines only. Any application of a pesticide must be in accordance with directions printed on the product label of that pesticide as prescribed under the Pest Control Products Act. Always read the label. A pesticide should also be recommended by provincial authorities. Because recommendations for use may vary from province to province, your provincial agricultural representative should be consulted for specific advice.

Agriculture Canada Publication 1499/E

available from

Communications Branch, Agriculture Canada

Ottawa K1A 0C7

- Minister of Supply and Services Canada 1990

Cat. No. A43-1499/1990E ISBN 0-662-17168-3

Printed 1973 Reprinted 1974 Revised 1990 5M-04:90

Également disponible en français sous le titre

Les mouches noires 
Digitized by the Internet Archive in 2013 


\section{CONTENTS}

\section{Introduction 7}

Life cycle 7

Behavior 8

Species affecting humans 8

Species affecting livestock 9

Cattle 9

Horses 10

Poultry 10

Sheep 10

Swine 11

Protection 11

Human protection 11

Clothing 11

Repellents 11

Livestock protection 11

Cattle 12

Horses 12

Poultry 13

Sheep and swine 13

Control 13

Planning a control program 13

Assessing severity of attack 13

Identification of problem species and breeding sites 14

Type of control 14

Larval control 14

Insecticides available 15

Equipment 15

Calculations for larviciding $\quad 15$

Application 16

Adult control 17

Insecticides available 17

Equipment 17

Application 17

Assessments and reports 18 


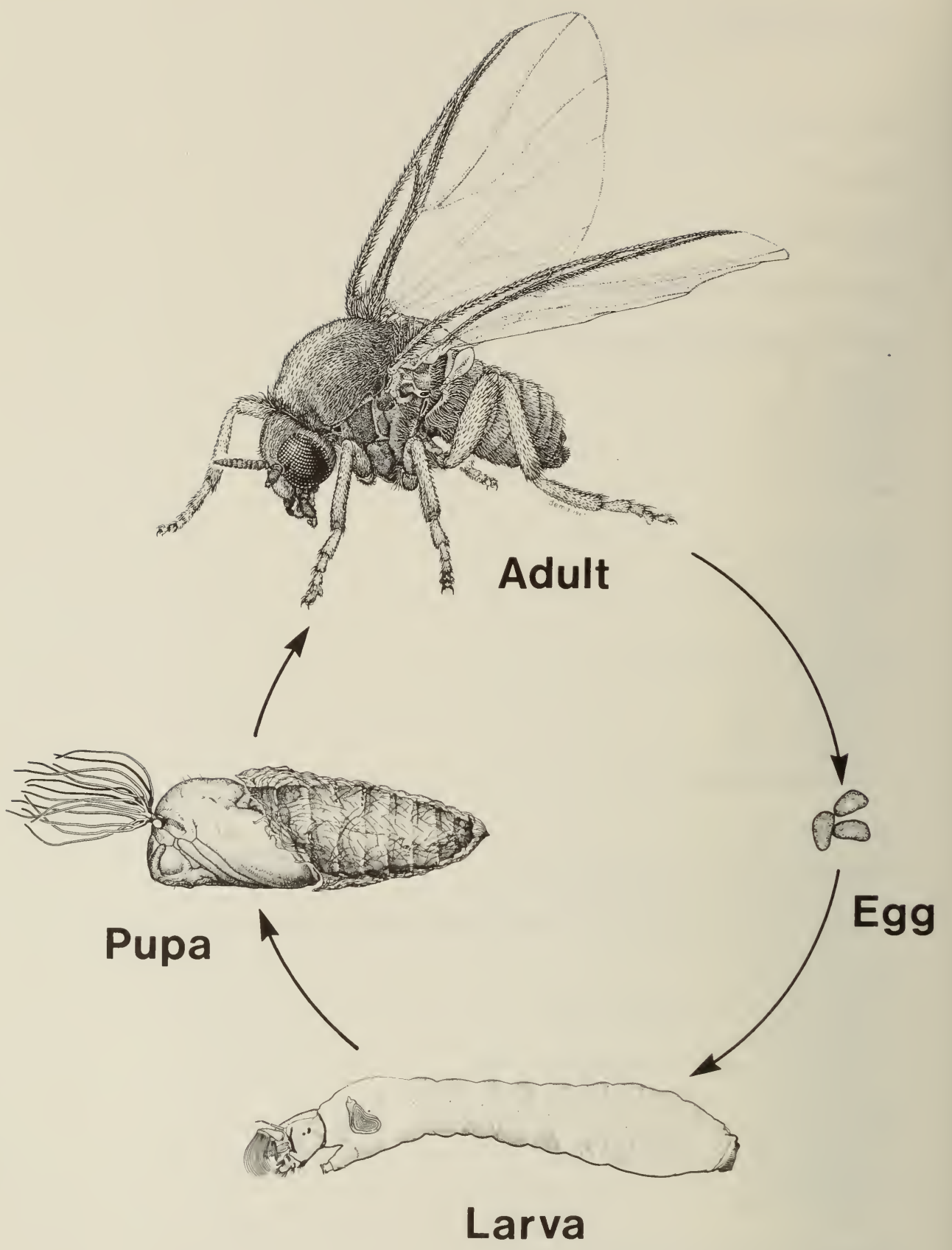

Fig. 1 Life cycle of black flies. (Drawings of larva, pupa, and adult reproduced, with permission of the Minister of Supply and Services Canada, adapted from McAlpine et al. 1981. Manual of Nearctic Diptera, Volume 1.) 


\section{INTRODUCTION}

Black flies, which number about 100 species in Canada, occur in varying abundance in all parts of the country. Adult females feed on blood, causing irritation and discomfort to humans, domestic and wild mammals, and birds. Apart from the annoyance and discomfort, black flies cause economic losses through reduced beef and milk production, reduced efficiency of agricultural and industrial workers, interference in recreation, reduced real estate values, spread of diseases, and interference with military operations. In Canada black flies are known to transmit blood-borne parasites to turkeys, geese, and ducks.

Black fly bites are painful and often result in allergic reactions in humans, which require medical attention. In cattle the allergic reactions may result in death. High numbers of adult females of Simulium arcticum Malloch from the Athabasca River and S. luggeri Nicholson \& Mickel from the Saskatchewan River have killed cattle and are considered a limiting factor in cattle production in these areas.

As black flies breed in flowing water in rivers, creeks, and irrigation canals they are usually abundant throughout the spring, summer, and early fall irrespective of precipitation. In some irrigation districts black flies are abundant enough to cause some distress to humans and livestock.

Successful abatement of black flies requires careful planning. Plans should be based on the species present, the location of their breeding sites, their behavior in relation to weather, and their host-seeking habits.

\section{LIFE CYCLE}

Black flies have four stages of development: egg, larva, pupa, and adult (Fig. 1). The eggs, larvae, and pupae are confined to rivers and streams. Some species lay eggs in masses on partially submerged plants and rocks; others scatter their eggs over the surface of a river. The eggs hatch within a few days or months, depending on the species, after which the larvae drift and attach themselves to rocks and vegetation in the swiftest flowing water. The greenish gray or brown larvae feed by filtering nutrients from the water and, at summer temperatures, grow to about $6 \mathrm{~mm}$. They pupate within 2 or 3 weeks.

After a few days in the pupal stage the adults escape from the pupa and float to the surface in an air bubble. Both adult male and female black flies feed on nectar and plant juices to sustain their energy requirements. Mating occurs soon after emergence. Females of biting species then seek blood, which they require to produce eggs. 
In southern Canada, black flies appear in April, reach maximum numbers in June and July, and persist until the first major frost in October. In more northerly latitudes the season starts later and ends sooner. Some species, such as S. luggeri, have more than one generation a year and numbers can reach outbreak levels if no measures are taken to suppress the populations.

Females of most black fly species require a blood meal to produce eggs. After locating a host, settling on its skin, and inserting their bladelike piercing mouthparts, the females suck blood until fully engorged. After taking the blood meal they are usually twice their normal size.

\section{BEHAVIOR}

Black flies are active during daylight hours but their rate of attack increases during morning and afternoon. On cloudy days or when storms are imminent black flies attack viciously at any time of day. Winds may disperse large numbers of adults from breeding areas to surrounding regions, especially open farmland. Shifting winds may disperse black flies to other districts. Cold or rainy weather usually ends an outbreak temporarily.

\section{SPECIES AFFECTING HUMANS}

S. venustum Say, S. verecundum Stone \& Jamnback, S. luggeri, S. decorum Walker, Prosimulium mixtum Syme \& Davies, and $P$. hirtipes (Fries) are the major pest species affecting humans in Canada. These species are dark brown to black and can occur at any time during the spring and summer months. Attacks can occur many kilometres away from suitable breeding grounds. Unlike mosquitoes, which normally attack in the evenings and early mornings, black flies attack their hosts throughout the day but rarely indoors.

S. vittatum Zetterstedt, a larger, gray species, is also attracted to humans and will occasionally bite. This species is more of a nuisance than a pest because it swarms around the head. S. griseum Coquillett, $S$. bivittatum Malloch, S. tuberosum Lundstrom, and S. parnassum Malloch are occasional pests of humans, especially in areas near small streams.

Black fly females are attracted to dark-colored clothing. They bite exposed parts of the body such as the back of the neck, along the hairline of the forehead and temple, the face, wrists, back of the hands, and around ankles. When populations are high black flies will crawl into ears, nose, and around the eyes. Black flies lacerate the skin and inject a strong anticoagulant from their saliva to prevent clotting of the blood in their mouth parts. The anticoagulant also causes blood to 
flow for some time after the female has left her host. A lesion usually develops at the site of the bite followed by an exudate, edema, and itching. Redness and edema can persist for up to $72 \mathrm{~h}$ and itching can persist for up to 1 week. Black fly bites can cause reactions such as local swelling, swelling of the lymph glands, and secondary infections as a result of scratching of the bites. Children are generally more susceptible to black fly bites than adults.

\section{SPECIES AFFECTING LIVESTOCK}

\section{CATTLE}

About 11 species of black flies are economically important as pests of cattle. S. arcticum and S. luggeri in Alberta and Saskatchewan and $S$. defoliarti Stone \& Peterson in certain intermontane valleys in British Columbia are noted for their vicious and sometimes fatal attacks on cattle. Bites usually occur on the belly, udder, and to a lesser degree on the legs, sides of the body, sides of the neck, face, and when populations are very dense, around the eyes. Cattle react to black flies by vigorous tail switching, stamping of feet, twitching of ears or skin, and a constant licking of the body. Under severe attack cattle seek shelter in barns or bushes or move to windy high spots in open areas where they stand or lie down in tight groups.

$S$. arcticum is usually a pest of cattle from early June to mid September. The females attack cattle during daylight hours, inflicting painful bites, sucking blood, and injecting toxic saliva through the bite. The saliva causes symptoms similar to anaphylactic shock and when large numbers of black flies bite newborn calves and other cattle not previously exposed to black fly bites, the anaphylaxsis is usually fatal. Other losses to the producer result from reduced grazing, unbred cows, and possible sterility in bulls.

$S$. luggeri is usually present from early June to early October. Like most other species, the females attack during daylight hours inflicting painful bites and sucking blood. S. luggeri is not known to cause death in cattle through injection of toxic saliva. However, in reaction to dense swarms, cattle become hyperactive, crowd together against fences, or even stampede. Losses to the producer result from reduced grazing, from injury and death caused by crowding and stampeding, and from interrupted breeding. Newborn calves may die from loss of blood. Since S. luggeri females bite around the eyes they are suspected transmitters of bovine keratitis.

$S$. defoliarti occurs in British Columbia during July and in some years annoys cattle. The attack by females is similar to that described for $S$. arcticum except that they do not inject a toxic saliva that will kill animals. 
S. vittatum is one of the first species to appear in the spring and can persist through the summer. Females attack ears of cattle and may cause severe dermatitis.

$S$. venustum and $S$. decorum bite cattle on all parts of the body where they can penetrate the hair coat. These species are not known to kill cattle.

Other species that attack cattle in Canada include $S$. tuberosum, $S$. griseum, $S$. parnassum, $P$. mixtum, and $P$. fulvum (Coquillett).

\section{HORSES}

S. arcticum, S. venustum, S. decorum, S. vittatum, and S. luggeri attack horses in Canada. Females of $S$. arcticum feed mainly on the forequarters and the under surface of the belly.

$S$. venustum and $S$. decorum females feed on almost every part of the body but appear to prefer the chest, side of the neck or head, and the inner surfaces of the legs. S. vittatum females feed mainly in the ears causing severe dermatitis. However, the mere presence of hovering flies around the head causes annoyance to horses.

$S$. luggeri females swarm around the head and bite around the face, particularly the eyes and muzzle, and the side of the neck. Bleeding and allergic reactions to the bites are a common characteristic of attack. The allergic reactions take the form of large wheals and bloody scabs on the skin surface. Horses become restless and unmanageable when ridden.

\section{POULTRY}

S. meridionale Riley, S. rugglesi Nicholson \& Mickel, and S. aureum Fries are the major pest species of poultry in Canada. The severity of attack varies in different parts of Canada, depending on the proximity of poultry to breeding sites of these bird-biting species. Poultry are usually attacked in the evening, causing the birds to become extremely restless. The flies feed on the combs, wattles, and around the eyes causing bleeding and scabs. All listed species are vectors of Leucocytozoon spp. blood parasites, which have become epidemic in turkeys, geese, ducks, and chickens.

\section{SHEEP}

$P$. fulvum, $P$. esselbaughi Sommerman, and $S$. vittatum are known as pest species of sheep in Canada. P. fulvum and $P$. esselbaughi are common in alpine pastures in British Columbia. $S$. vittatum is common in the prairies, particularly in irrigated areas. Females of these species bite around the head causing the sheep to panic and to form very tight groups as a protective reaction. Losses to the producer result from either reduced weight gains caused by less grazing and 
injuries sustained while clustered together, or even death of animals from suffocation.

\section{SWINE}

$S$. venustum and $S$. arcticum are known to attack hogs raised outdoors. Attacks by these flies cause sows to be barren and to suffer from swollen and infected udders. Breeding stock that has not been exposed previously to black flies requires protection to prevent death from the toxic saliva of $S$. arcticum.

\section{PRO'TECTION}

\section{HUMAN PROTECTION}

Harassment of people by black flies can be reduced in several ways. Attack can be reduced by wearing suitable clothing, using repellents, or avoiding outdoor activities during periods of peak black fly activity. Black fly attacks are usually more severe in the morning, late afternoon, and early evening or when storm clouds are present. They are also more severe in wooded areas than in open areas.

\section{Clothing}

Light-colored clothing is least attractive to blood-seeking females. Loose-fitting garments with zippers, fastened shirt sleeves, and pant legs tucked into socks or boots prevent black flies from crawling into the spaces between the clothing and the body. Head nets made of fine-mesh material can protect the head and neck.

\section{Repellents}

Repellents, applied thinly and evenly, provide good protection from black flies. Commercial repellents contain active ingredients such as $N, N$-diethyl- $m$-toluamide (deet), 2-ethyl-1,3-hexanediol (6-12), citronyl, and dimethyl phthalate. The most effective are those with high concentrations of the active ingredient. Care should be exercised when applying repellents to keep them out of eyes, mouth, and nose. Always read the instructions on the container before using repellents. Repellents applied to clothing have a long-lasting effect. Jackets impregnated with repellents are available commercially.

\section{LIVESTOCK PROTECTION}

Livestock can be protected from black fly attack by raising animals as far away as possible from black fly breeding grounds; by 
providing shelters so animals can enter and avoid attack during periods of intense activity; by treating animals with insecticides or repellents; and by implementing a larviciding program. Several insecticides and repellents are available commercially, which should be used as directed on the label.

\section{Cattle}

Shelters, that provide dark conditions into which black flies will not fly are effective in providing relief to cattle from attack. Shelters, which need not be expensive to be effective, should be not only large and strong enough to accommodate the herd but also dark enough to repel black flies from entering. Structures consisting of three solid walls and a roof are usually adequate. A shelter $6 \mathrm{~m}$ wide, $12 \mathrm{~m}$ deep (front to back), and $2.5 \mathrm{~m}$ high with two solid sides, one end wall, and a roof proved to be adequate for 20 mature cattle. Cattle learn quickly to use the shelters. On some farms, barns or other outbuildings can be used as shelters. Self-application devices for repellents and insecticides can be installed to treat cattle as they enter or leave the shelter, which gives an added advantage to the use of shelters.

Insecticide treatments must cover most of the animal's body to be effective. Several formulations of repellents and insecticides are available commercially that can be used to protect cattle from black flies. Only those specifically recommended for black flies should be used and the label instructions should be followed carefully. Restrictions on use before slaughter or freshening must be followed.

An electrostatic sprayer has been developed that allows efficient application of repellents or insecticides to cattle under pasture conditions. The insecticide or repellent solution is dispersed as charged droplets that are attracted to the hair of the animals. The advantages of this sprayer are that animals need not be restrained or penned to achieve total body coverage, small amounts of spray solution are required, and little time is needed to treat the animals.

Back rubbers, charged with insecticides or repellents, in a free- or forced-use situation, provide protection from black flies with minimum handling of animals. Free-use applicators are placed in pasture or yard locations where animals have access to them whenever they desire to use them. Forced-use applicators are installed in entrances to fenced-in mineral or water sources. In this way the animals receive a repellent or insecticide treatment every time they enter and leave the enclosure. This method of application is more effective than the free-use method.

\section{Horses}

Shelters, similar to the ones described for cattle protection, can also provide horses with a refuge for temporary relief from black fly attack. Commercial repellents are available and should be used as 
directed on the label. Application of white petroleum jelly to the inside of the horses' ears is effective in reducing attack by species that bite the ears.

\section{Poultry}

Poultry can be protected from black fly attack by keeping them indoors during the evenings especially during periods of intense black fly activity.

\section{Sheep and swine}

Sheep and swine can be offered temporary relief from black fly attack by having access to shelters as described for cattle.

\section{CONTROL}

\section{PLANNING A CONTROL PROGRAM}

Although no set criteria exist for justifying a control program, the following factors should be assessed: severity of black fly attack, proximity to breeding sites, and cost of monitoring and control. Qualified personnel should be contacted to assist in developing a program for black fly control that will be cost-effective and environmentally acceptable.

\section{Assessing severity of attack}

Activity and abundance of adult black flies should be assessed to determine whether control measures are required. Several methods can be used to estimate the severity of attack by adults. Some common methods are the use of landing rate count, sticky traps, and silhouette traps. As species respond differently to different assessment methods, the method used will depend on the objective of assessment and the species present.

Landing rate count, which consists of placing a square piece $(30 \times$ $30 \mathrm{~cm}$ ) of dark cloth, preferably blue, on a person's body and counting the number of flies that land on the cloth over a specified time, is a useful method to assess populations of black flies that are attracted to humans.

Sticky traps, which consist of paint cans or other types of cylindershaped objects, painted blue and covered with a sticky material, are useful in catching black flies that are present in the area.

Silhouette traps, which consist of a wood or metal frame similar in shape and size to a cow or calf, covered with dark cloth, or a wood body 
with a cloth border, on all sides except the bottom, and a collecting chamber on top are useful in collecting black flies that normally attack cattle.

Each method provides quantitative information that can be related to irritation levels, determined by observing behavioral patterns of humans or animals, to define the severity of attack. The information can also be used to determine the timing of control measures.

\section{Identification of problem species and breeding sites}

Specimens from adult and larval sampling devices should be preserved in rubbing alcohol or gas-line antifreeze. Location of larval breeding habitats can be determined by examining, for larvae and pupae, rocks and vegetation in fast-flowing stretches of streams, rivers, and irrigation canals. Adult, larval, and pupal samples should be preserved, labeled according to location and collection date, and sent to a specialist for identification. When the problem species and their breeding sites are determined, and the attack is considered to be severe enough, a control program can be implemented.

\section{Type of control}

Insecticidal control of adults or larvae is the most common method of controlling black flies. A specialist should supervise this type of program. Control programs should be planned well in advance of the black fly season and executed in consultation with an entomologist to ensure that the best control is achieved with minimum harmful effects on the environment. All provincial acts and regulations pertaining to the use of insecticides must be followed closely.

\section{LARVAL CONTROL}

The most effective control measures against black flies are those aimed at the larval stage. Because this stage is restricted to streams and rivers and thus concentrated in a confined area, its treatment is the most effective and economical. At known breeding sites, a carefully calculated concentration of larvicide injected into the water kills the larvae and thus reduces black fly numbers.

Black flies emerge over an extended period during the summer and several larvicide applications into a river or stream would be required to reduce larval numbers significantly. However, insecticides, particularly the biological agent Bacillus thuringiensis israelensis (Bti or BTH-14), are very expensive. Thus, a larval control program should aim to kill the greatest number of larvae possible with a single application of larvicide. Once the relationship between larval populations in the river and the resulting adult population is determined, cost-effective control of larval black flies, through 
quantitative monitoring of population levels, can be implemented. Such monitoring of larval numbers will permit early warning of potential outbreaks. More intensive larval control can then be planned. Larval populations can be monitored by setting out artificial substrates (lengths of rope or strapping tape), to which black fly larvae attach, in fast-flowing water of the river or stream to be treated. When larvae reach sufficient numbers, determined by relating numbers of larvae present to the severity of attack levels, as observed on the artificial substrates, a decision is made to treat the breeding sites.

\section{Insecticides available}

Recommendations for black fly control change as newer and better insecticides become available. Contact your provincial agriculture representative or fieldperson or Agriculture Canada for current larvicides.

\section{Equipment}

On a large scale, larvicides can be applied by helicopter at known breeding sites along the length of a river. A map identifying these sites allows the pilot to apply appropriate dosages at each location. The method is fast but costly.

Smaller-scale programs involve applying the insecticide, from a boat or traffic ferry, either undiluted or diluted. A variety of techniques including barrels, backpack sprayers, or a watering can, can be used depending upon the amount required and the type of stream. These methods of application are cheaper than the helicopter method but can be time-consuming if numerous sites must be treated.

Small streams can be treated using a backpack sprayer or watering can.

\section{Calculations for larviciding}

To determine the amount of insecticide required, the stream discharge and dosage required must be known. To calculate the discharge of flowing water, determine the width and average depth of the stream in metres, at a point upstream from the area to be treated. Measure the velocity of the stream, in metres per second, at several points using a hydrographic flowmeter, or by timing a floating object over a measured distance not less than $5 \mathrm{~m}$. The object should be heavy enough that it is not affected by wind. The average velocity, using the latter method, is about two-thirds of the measured surface velocity. The stream discharge then is calculated:

Width $(\mathrm{m}) \times$ Average depth $(\mathrm{m}) \times$ Velocity $(\mathrm{m} / \mathrm{s})=$ Discharge $\left(\mathrm{m}^{3} / \mathrm{s}\right)$ 
Water levels in larger rivers may be measured by automatic gauge that can be accessed by phone. If the gauge does not provide a discharge reading, consult the agency responsible for its operation for advice on how to calculate discharge from the water level readings provided.

Once discharge is known and a decision made on the application rate (dosage), use of the following calculations allows the determination of the amount of insecticide needed:

\section{Amount required $=$ Discharge $\times$ Application rate}

If a stream, with a discharge of $10 \mathrm{~m}^{3}$ of water per second, is to be treated with methoxychlor at $0.3 \mathrm{ppm}$ for $15 \mathrm{~min}$ then the calculations are as follows:

$10 \mathrm{~m}^{3}$ of water per second $=1 \times 10^{7} \mathrm{~g} / \mathrm{s}=900 \times 10^{7} \mathrm{~g} / 15 \mathrm{~min}$.

The amount of active ingredient of methoxychlor required to maintain a concentration of $0.3 \mathrm{ppm}$ for $15 \mathrm{~min}$ in a river flowing at a discharge of $10 \mathrm{~m}^{3} / \mathrm{s}$ is: $\left(900 \times 10^{7} \times 0.3\right) / 10^{6}=2700 \mathrm{~g}$ a.i. Because there is $1 \mathrm{~g}$ a.i. per $4.17 \mathrm{~mL}$ of concentrate, then the amount of concentrate required for a river of this discharge is:

$2700 \times 4.17=11259 \mathrm{~mL}$ of concentrate or $11259 / 1000=11.26 \mathrm{~L}$.

The biological insecticide Bacillus thuringiensis israelensis (Bti) is used at a variety of rates, depending on concentration of the formulation and dosage desired. The label gives formulation concentration and recommended doses. For example, a product with a formulation concentration of 1200 international toxicity units per milligram is used at concentrations from $1 \mathrm{ppm}$ for $15 \mathrm{~min}$ to $25 \mathrm{ppm}$ for $1 \mathrm{~min}$. Thus the required amount to treat a stream with a discharge of $10 \mathrm{~m}^{3} / \mathrm{s}$ at a rate of $1 \mathrm{ppm}$ for $15 \mathrm{~min}$ will be:

$\left(10 \mathrm{~m}^{3} / \mathrm{s} \times 60 \mathrm{~s}=600 \mathrm{~mL} / \mathrm{min}\right.$ of stream flow $)$

$\times(1 \mathrm{ppm} \times 15 \mathrm{~min})=9000 \mathrm{~mL}=9 \mathrm{~L}$.

\section{Application}

The insecticide is applied across the width of stream or river for the time specified by the rate (see formulae for calculating insecticide concentration). The point of application must be located far enough upstream from the larval habitat that the insecticide is properly dispersed in the water passing over the infested area. For example, to treat lake outflows or beaver pond outflows the insecticide should be injected far enough into the lake or pond so that it will settle enough to be pulled into the outflow and over the lip. Nearer the outflow, the insecticide can be applied to the bottom or close to it through a hose from a boat. In large rivers, like the Athabasca and the Saskatchewan, the method of injection should be chosen to ensure thorough dispersion and mixing to achieve uniformity of concentration. It is important to know what is the effeclive "carry" (to what distance $80 \%$ or more of the larvae are killed) of the insecticide by the water to determine the 
number of locations in the treatment area at which insecticide must be applied. Another consideration is the interval between treatments. If a first treatment does not significantly reduce the larval numbers, further treatments may be required. In addition, black fly species that have more than one generation per year will require repeated treatments throughout the year.

Personnel with experience in monitoring larval populations should be consulted when a larvicide program is being considered because they know the techniques needed to develop an effective program. A permit from the provincial environment department is required whenever insecticides are applied to flowing water.

\section{ADULT CONTROL}

Temporary relief from adult black flies can be obtained from proper use of spatial sprays. A spatial spray is a fine spray, mist or aerosol, consisting of very small droplets of insecticide solution that are dispersed by movements of air. The droplets contact adult black flies that are in flight or at rest. However, because spatial sprays produce no effective residual deposits of insecticides, the relief is temporary and treatments may have to be repeated daily while adults are a problem.

Spraying of vegetation in farmyards, around forest work camps, camp grounds, and recreational facilities with insecticides that have residual properties will provide temporary relief from black fly attack. The insecticide may be applied as a fine mist or a light spray.

\section{Insecticides available}

Insecticide recommendations for black fly control change as newer and better materials become available. Consult your provincial agriculture representative or fieldperson or Agriculture Canada for information on current adulticides.

\section{Equipment}

A compressed-air sprayer fitted with a fine-spray nozzle or an aerosol generator can disperse the adulticide sufficiently to reduce adult black fly numbers temporarily in confined areas. Aerosol generators can disperse insecticide mixture at up to $454 \mathrm{~L} / \mathrm{h}$ over large areas. A cloud of very fine droplets is produced and will disperse by wind.

\section{Application}

The compressed-air sprayer should be filled three-quarters full with the chosen insecticide and the air compressed by using the hand 
pump. Spraying can take place until the pressure drops to a level at which the spray becomes uneven. At this point the pressure should be increased again by using the hand pump.

When using a fogger (thermal aerosol generator), the insecticide should be applied just before sunset or just before sunrise, when black fly adults are most active. Wind speeds $<10 \mathrm{~km} / \mathrm{h}$ are ideal for ground dispersal. The generator should be moved in parallel lines, at 5 or $6 \mathrm{~km} / \mathrm{h}$, working upwind at intervals of $200-350 \mathrm{~m}$. When using an aerosol generator in areas where there is a fire hazard, a water emulsion rather than an oil solution of insecticide should be used.

\section{ASSESSMENTS AND REPORTS}

The effectiveness of control measures should be assessed within $48 \mathrm{~h}$ of insecticidal applications. Documenting the control procedures and monitoring the results is an important part of the program. Records of larval and adult numbers during the black fly season provide important information for continuing or modifying a control program. A summary or annual report written at the end of the season will greatly help in planning future programs. The report should include information on population trends, insecticide treatment schedules, quantities of insecticides used, areas covered, treatment methods, costs, and any other pertinent facts. Forecasts can also be prepared based on the information recorded. 


\section{CONVERSION FACTORS FOR METRIC SYSTEM}

Imperial units

Linear

$\begin{array}{ll}\text { inch } & \times 25 \\ \text { foot } & \times 30 \\ \text { yard } & \times 0.9 \\ \text { mile } & \times 1.6\end{array}$

Area

square inch

square foot

acre

Volume

$\begin{array}{ll}\text { cubic inch } & \times 16 \\ \text { cubic foot } & \times 28 \\ \text { cubic yard } & \times 0.8 \\ \text { fluid ounce } & \times 28 \\ \text { pint } & \times 0.57 \\ \text { quart } & \times 1.1 \\ \text { gallon } & \times 4.5\end{array}$

Weight

$\begin{array}{ll}\text { ounce } & \times 28 \\ \text { pound } & \times 0.45 \\ \text { short ton }(2000 \mathrm{lb}) & \times 0.9\end{array}$

Temperature

degrees Fahrenheit

$\left({ }^{\circ} \mathrm{F}-32\right) \times 0.56$

or $\left({ }^{\circ} \mathrm{F}-32\right) \times 5 / 9$

$$
\begin{aligned}
& 6.5 \\
& \times 0.09 \\
& \times 0.40
\end{aligned}
$$

Results in

$\begin{aligned} \text { millimetre } & (\mathrm{mm}) \\ \text { centimetre } & (\mathrm{cm}) \\ \text { metre } & (\mathrm{m}) \\ \text { kilometre } & (\mathrm{km})\end{aligned}$

$$
\begin{aligned}
\text { square centimetre } & \left(\mathrm{cm}^{2}\right) \\
\text { square metre } & \left(\mathrm{m}^{2}\right) \\
\text { hectare } & (\mathrm{ha})
\end{aligned}
$$

$$
\begin{aligned}
\text { cubic centimetre } & \left(\mathrm{cm}^{3}, \mathrm{~mL}^{3} \mathrm{cc}\right) \\
\text { cubic decimetre } & \left(\mathrm{dm}^{3}\right) \\
\text { cubic metre } & \left(\mathrm{m}^{3}\right) \\
\text { millilitre } & (\mathrm{mL}) \\
\text { litre } & (L) \\
\text { litre } & (L) \\
\text { litre } & (L)
\end{aligned}
$$

$$
\begin{aligned}
\text { gram } & (\mathrm{g}) \\
\text { kilogram } & (\mathrm{kg}) \\
\text { tonne } & (\mathrm{t})
\end{aligned}
$$

\section{degrees}

Celsius $\left({ }^{\circ} \mathrm{C}\right)$

\section{Pressure}

pounds per square inch $\times 6.9$

kilopascal (kPa)

Power

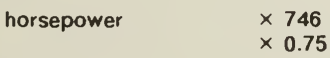

$$
\begin{aligned}
\text { watt } & (\mathrm{W}) \\
\text { kilowatt } & (\mathrm{kW})
\end{aligned}
$$

\section{Speed}

feet per second

$$
\begin{array}{ll}
\times 0.30 \\
\times 1.6
\end{array}
$$

metres per second $(\mathrm{m} / \mathrm{s})$ miles per hour

$$
\begin{aligned}
& \times 11.23 \\
& \times 2.8 \\
& \times 1.4 \\
& \times 70 \\
& \times 2.24 \\
& \times 1.12 \\
& \times 70 \\
& \times 2.47
\end{aligned}
$$

kilometres per hour $(\mathrm{km} / \mathrm{h})$

$\begin{aligned} \text { litres per hectare } & \text { (L/ha) } \\ \text { litres per hectare } & \text { (L/ha) } \\ \text { litres per hectare } & \text { (L/ha) } \\ \text { millilitres per hectare } & (\mathrm{mL} / \mathrm{ha}) \\ \text { tonnes per hectare } & (\mathrm{t} / \mathrm{ha}) \\ \text { kilograms per hectare } & \text { (kg/ha) } \\ \text { grams per hectare } & \text { (g/ha) } \\ \text { plants per hectare } & \text { (plants/ha) }\end{aligned}$


